\title{
RELATION BETWEEN WORK ENVIRONMENT AND NURSES' BURNOUT AT MANSOURA HEALTH INSURANCE HOSPITAL
}

\author{
Aza Saif Elsais ${ }^{1}$, Karima Ahmed Elsayed ${ }^{2}$, Reda Shehata Elsayed ${ }^{3}$ \\ ${ }^{1}$ B.S.c Nursing - Mansoura University \\ ${ }^{2}$ Assistant professor of Medical -Surgical Nursing Department, Faculty of Nursing, Mansoura University \\ ${ }^{3}$ Professor of Medical-Surgical Nursing Department, Faculty of Nursing, Mansoura University
}

\begin{abstract}
Background: Nursing is a stressful profession that deals with human aspects of illness and health. It requires the provision of human, empathetic, skilled and ethical care, in work environment with increasing responsibilities and restricted resources. The inequity between providing high-quality care and managing the stressful work environment can lead to burnout. Aim: The aim of this study was to study the relation between work environment and nurses' burnout at Mansoura Health Insurance Hospital. Research design: A descriptive correlation design was used. The study was conducted at Mansoura Health Insurance Hospital. Subjects of the study: Subjects were included (196) nurses. Two tools were used for data collection, work environment scale, and burnout inventory. Results and conclusion: Findings revealed that $49.5 \%$ of nurses had negative perception regarding their work environment and $34.7 \%$ had a moderate level of burnout. The correlation between work environment and burnout was negative. Recommendations: Improving nursing work environment and management of burnout through providing a supportive environment, clarifying roles and responsibilities, and providing regular training courses for the nurses on coping strategies.
\end{abstract}

Key words: Work Environment, Nurses Burnout

\section{Introduction:}

Today, most organizations pay attention to the fundamental staff and they try to provide a positive work environment. The complete work environment includes physical, psychological and social features that define the working condition. This involves all the characteristics that impact and affect the whole body and awareness of an individual (Mehboob and Bhutto, 2012) ${ }^{1}$. Work environment plays an essential role in motivating individuals to do their assigned work (Chandrasekar, 2011) $)^{2}$.

World Health Organization specifies that the working environment is an essential aspect in the staffing and maintenance of health professionals, and the features of the workplace directly, and indirectly affect the quality of care (Wiskow et al., 2010) ${ }^{3}$. Moos $(\mathbf{2 0 0 8})^{4}$ divided work environment into three dimensions which are the relationship, personal development or goal direction and system maintenance and system change.

Chandrasekar $\left(\mathbf{2 0 1 1}^{\mathbf{2}}\right.$ mentioned that work environment factors are the space and facilities to do the work, equal treatment at the place of work, workplace communication system, relationship with superiors to work, performers of the environment are favorable to work, and processes to recognize and inhibit risks.

Wallgren (2011) ${ }^{\mathbf{5}}$ stated that features of the work environment are diversity in responsibilities, career autonomy, the opportunity to acquire new skills, praise for a job well done, and a sense of 
accomplishment. While Mehboob and Bhutto (2012) ${ }^{\mathbf{1}}$ identified features of the work environment which are clear and open communication, the stabilization of working life, independence, and the situation of the stability and predictability. Liu et al., (2012) ${ }^{6}$ reported that poor work environment was linked with burnout and specifically work-life parts, for example control, workload, reward, fairness values, and community (Maslach and Leiter, 2009) ${ }^{7}$.

Burnout simplifies the largest amount of alteration in health care provider (Khamisa, 2015) $^{\mathbf{8}}$. According to Barlem et al., (2014) ${ }^{9}$ burnout is a problem of social concern, following a long process of exposure to high levels of stress, under different situations, causing physical, mental and emotional exhaustion.

Burnout among nurses relates to negative health outcomes (Maslach and Leiter, 2008) $)^{10}$. Most of the results that were studied were associated with job performance, occupational health outcomes, characteristics related to work environment and individual factors (Morse, 2012) $^{\mathbf{1 1}}$. As burnout is linked with these solvable issues with requirements to work, the autonomy of nurses and social support in the workplace (Pisanti et al., 2013) ${ }^{12}$.

Work-related consequences of burnout can include dissatisfaction with the work, mistakes in the healthcare provided, reduction in the quality of care, intention of giving up the job, unreasonable absenteeism, and leaving. Lastly, the impact on the environment of the workers includes work-home conflict, family problems, and reduction in the quality of life (Suñer-Soler et al., 2014) ${ }^{13}$.

Burnout composed of three categories of emotional exhaustion, depersonalization in addition to lack of personal accomplishment. Burnout disorder is recognized by symptoms of fatigue, longterm hard work, a sense of self-pressure, forgetfulness of one's own needs, commitment to an external factor, being influenced by the managerial staff and excessive attention to the clients' needs (Alidosti et al., 2016) $^{14}$.

\section{Significance of the study}

Nursing is a stressful profession that deals with human aspects of health and illness. It requires the delivery of human, empathetic, skillful and ethical care, in work environment with limited resources and increasing responsibilities. Such imbalance between providing high-quality care and coping with stressful work environment can lead to burnout and negatively affect the quality of care, patient satisfaction and organizational cost (Khamisa, 2015) $^{\mathbf{8}}$. On the other hand, the prevalence of nurse burnout is minimized in a professional work environment that enable and encourage complete opportunity for nursing practice. So the aim of this study is to study the relation between work environment and nurses' burnout at Mansoura Health Insurance Hospital.

\section{Aim of the Study}

This study was aimed to study the relation between work environment and nurses' burnout at Mansoura Health Insurance Hospital.

\section{Research Questions:}

RQ1: What are the nurses' perception toward the work environment at Mansoura Health Insurance Hospital?

RQ2: What are the levels of nurses' burnout at Mansoura Health Insurance Hospital?

RQ3: Is there a relation between work environment and nurses' burnout at Mansoura Health Insurance Hospital? 
RELATION BETWEEN WORK ENVIRONMENT AND etc...

V. Subjects and Methods
Design of study
A descriptive correlation design was used
to carry out this study.

\section{Setting:}

The present study was conducted at Mansoura Health Insurance Hospital which affiliated to the ministry of health with a bed capacity (300) beds. It consists of 6 floors containing 13 units / departments as follow: emergency department, surgical intensive care unit, urinary tract department, obstetrical and gynecology, cardiac intensive care unit, surgical departments, children department, orthopedics department, nose and ear department, medical departments, neonates unit, economic department, and dialysis unit.

\section{Subjects}

Subjects were included 196 nurses with a minimum of one year experience. $37.8 \%$ of the studied nurses were working in surgical units. Concerning age, the majority (80.6) of nurses' age were in age group from 20 to 30 years old. The majority $(84.7 \%)$ of nurses were married. More than half $(50.5 \%)$ of nurses had 3 years diploma degree in nursing. Regarding years of experience, $43.9 \%$ of nurses had less than 10 years of experience. Majority $83.2 \%$ of nurses were staff nurses.

\section{Data Collection Tools:}

The data from this study were collected using two tools:

Tool I: Work Environment Scale: It was consisted of two parts.

First part: It was included information on personal characteristics as, department, age, marital status, educational qualification, years of experience and current position.

Second part: Work Environment Questions: This instrument was developed by Moos (1994) ${ }^{15}$ and adjusted by the researcher. The aim was to assess nurses' perception regarding their work environment as positive or negative.

It was consist of 90 items categorized into three broad dimensions which are:

a) Relationship dimension was consist of (27) items divided into three subscales namely: involvement, peer cohesion, and supervisor support. Each subscale consisted of (9) items.

b) Personal growth dimension was consist of (27) items divided into three subscales namely: autonomy, task orientation, and work pressure. Each subscale consisted of (9) items.

c) System maintenance and system change dimension was consist of (36) items divided into four subscales namely: clarity, managerial control, innovation, and physical comfort. Each subscale consisted of (9) items.

\section{Scoring system}

The score ' 1 ' is assigned to true items and ' 0 'to false items. Scores range from 0 to 9 on each nine subscales and total score range between 0 to 90 .

- Median scores considered as average $=50$

Below median scores as negative $=<50$

Above median scores were considered as positive $=>50(\text { Maqsood }, 2011)^{16}$.

Tool II: Maslach Burnout Inventory (MBI): It was established by Maslach et al., (1996) ${ }^{17}$ and adjusted by the researcher. It was aimed to assess the levels of burnout among nurses. It was consist of 22 items categorized into three subscales namely emotional exhaustion ( 9 items), depersonalization (5 items) and lack of personal accomplishment (8 items).

\section{Scoring system}

The subjects' response was measured on a five-point Likert scale ranging from (1) never to (5) every day. The range of scores was calculated for each of the three 
dimensions: emotional exhaustion (9-45), depersonalization (5-25) and personal achievement (8-40). High scores of emotional exhaustion and depersonalization, but low scores of personal accomplishment shows a high level of burnout.. The scores for each subscale were computed separately and classified as low, moderate or high using cutoff scores based on tertiles (Lin et al., 2013) ${ }^{18}$.

- Emotional exhaustion

-High: $\geq 41$

-Moderate: 32-40.9

-Low: $<32$

- Depersonalization

-High: $\geq 9.2$

-Moderate: 7-9.1

-Low: $<7$

- Personal accomplishment

-High: < 29

-Moderate: 29-32.9

-Low: $\geq 33$

\section{Validity:}

In order to enhance the package's content validity, five experts one professor assistant and four lecturers of Nursing Administration Department from Faculty of Nursing at Mansoura University were asked for their opinion on the package's construction and look to any ambiguities. Each one of them was handed a questionnaire package into English and Arabic to review, clarity, relevance, applicability, comprehensiveness, understanding, and ease for implementation.

\section{Reliability of data collection tool}

Tool reliability was assessed through estimating its internal consistency. It proved to be of good reliability, where Cronbach alpha coefficient was.76 for Work Environment Scale and .82 for Maslach Burnout Inventory

\section{Fieldwork}

Collecting data from staff nurses by explaining to each participant the aim of the study and take her acceptance. They were assured that the information given would be utilized confidentially and used for the research purpose only, and the researcher explained to them how to fill in the sheets.

Filling the questionnaire sheet about nurses' perception regarding their work environment and their feeling took from 20-30 minutes; this time was depending on the working conditions. Data collection for a few participants was carried out through the distribution of the questionnaire sheet to the topics and bimanual back to the researcher upon completion. Fieldwork of this study was carried out in nearly three months from 25/9/2015 to the end of December 2015.

\section{Ethical considerations}

The principles of ethics in research were closely followed in this study. The proposal was approved by the ethics committee. The participants gave their verbal consent to participate after being briefed with the study aim and procedures. They were informed about their rights to refuse or withdraw. Anonymity and confidentiality of the obtained information were assured.

\section{Pilot study:}

A pilot study was conducted of 20 $(10 \%)$ of nurses to test the clarity, feasibility of the questions and their understanding, and determine the time required to complete the questions. Nurses responded well to the questionnaire during the pilot study and no questionnaire changes were requested.

\section{Statistical Design:}

Data entry and statistical analysis were performed by using Statistical Package for Social Science (SPSS), version (16.0). 
RELATION BETWEEN WORK ENVIRONMENT AND etc...

Descriptive statistics were used where; quantitative data were presented as mean and standard deviation; while qualitative data were presented using frequency and percentage. Statistical presentation and analysis of the current study were conducted using mean, standard, t-test and

\section{Results}

f-test. Pearson Correlation (r) test and $\mathrm{p}$ value were used to test the proximity of relationship between two variables. Statistical significance was reflected at $\mathrm{p}$ value $<0.05$ while, the $\mathrm{p}$-value of $<0.001$ point to a high significant result.

Table(1): Levels of Nurses' Perception Regarding Their Work Environment

\begin{tabular}{|l|c|c|}
\hline Work Environment & \multicolumn{2}{|c|}{$(\mathbf{n}=196)$} \\
\cline { 2 - 3 } Average & No & $\%$ \\
Negative & 6 & 3.1 \\
Positive & 97 & 49.5 \\
\hline
\end{tabular}

Table (1): reveals nurses' perception regarding their work environment. As shown in the table nearly half $(49.5 \%)$ of nurses had negative perception regarding their work environment. While, $47.4 \%$ of nurses had positive perception regarding their work environment.

Table (2): Mean \pm SD Scores for Work Environment among Nurses $(n=196)$

\begin{tabular}{|l|c|}
\hline \multicolumn{1}{|c|}{ Work Environment Subscales } & Mean \pm SD \\
\hline Relationship & $12.8 \pm 3.03$ \\
\hline Involvement & $4.9 \pm 1.4$ \\
Median (min - max) & $5(2-9)$ \\
\hline Peer Cohesion & $4.3 \pm 1.7$ \\
Median (min - max) & $4(1-9)$ \\
\hline Supervisor support & $3.6 \pm 1.7$ \\
Median (min - max) & $4(0-9)$ \\
\hline Personal growth & $16.9 \pm 3.2$ \\
\hline Autonomy & $4 \pm 2.2$ \\
Median (min - max) & $4(0-8)$ \\
\hline Task orientation & $6.4 \pm 1.8$ \\
Median (min - max) & $7(1-9)$ \\
\hline Work pressure & $6.5 \pm 1.3$ \\
Median (min - max) & $7(2-9)$ \\
\hline System maintenance and system change & $19.6 \pm 4.8$ \\
\hline Clarity (min - max) & $4.6 \pm 1.7$ \\
Median (mil - & $5(0-8)$ \\
\hline Manageriantrol & $6.9 \pm 1.7$ \\
Median (min - max) & $7(0-9)$ \\
\hline Innovation & $3.5 \pm 2.2$ \\
Median (min - max) & $3(0-9)$ \\
\hline Physical comfort & $4.6 \pm 1.6$ \\
Median (min - max) & $5(0-8)$ \\
\hline Total work environment & $49.3 \pm 8.7$ \\
Median (min - max) & $50(25-69)$ \\
\hline
\end{tabular}

Table (2): illustrates Mean \pm SD scores for work environment among nurses. Findings revealed that nurses perceived their working environment negatively where mean scores were $49.2 \pm 8.7$. It can be noticed that managerial control subscales had the highest mean scores $(6.9 \pm 1.7)$, while innovation subscale had the lowest mean scores $(3.5 \pm 2.2)$. 
Aza Saif Elsais et. al.

Table (3): The Relation between Nurses' Perception Regarding Work Environment and Their Personal Characteristics

\begin{tabular}{|c|c|c|c|c|}
\hline \multirow{3}{*}{ Personal characteristics } & \multicolumn{4}{|c|}{ Work environment } \\
\hline & \multicolumn{2}{|c|}{$(n=196)$} & \multirow{2}{*}{ Mean \pm SD } & \multirow{2}{*}{ Significance test } \\
\hline & No & $\%$ & & \\
\hline $\begin{array}{l}\text { Department } \\
\text { Medical }\end{array}$ & 53 & 27.0 & $52.3 \pm 6.9$ & \multirow{4}{*}{$\begin{array}{l}\mathrm{F}=5.3 \\
\mathrm{P}=0.002 *\end{array}$} \\
\hline Surgical & 74 & 37.8 & $46.7 \pm 8.5$ & \\
\hline Special units & 63 & 32.1 & $49.9 \pm 9.3$ & \\
\hline Administration & 6 & 3.1 & $44.5 \pm 9.4$ & \\
\hline $\begin{array}{l}\text { Age(years) } \\
20-30 \\
20-30\end{array}$ & 158 & 80.6 & $49.3 \pm 8.7$ & \multirow[t]{2}{*}{$\begin{array}{l}t=0.5 \\
P=0.6\end{array}$} \\
\hline$>30$ & 38 & 19.4 & $48.6 \pm 9.2$ & \\
\hline $\begin{array}{l}\text { Marital status } \\
\text { Married }\end{array}$ & 166 & 84.7 & $49.3 \pm 8.2$ & \multirow{3}{*}{$\begin{array}{l}F=2.6 \\
P=0.08\end{array}$} \\
\hline Single & 25 & 12.8 & $48.8 \pm 10.2$ & \\
\hline Others & 5 & 2.5 & $48.0 \pm 15.9$ & \\
\hline $\begin{array}{l}\text { Educational Qualification } \\
\text { Diploma Degree in Nursing }\end{array}$ & 99 & 50.5 & $49.3 \pm 8.4$ & \multirow{3}{*}{$\begin{array}{l}F=0.3 \\
P=0.8\end{array}$} \\
\hline Associated Degree in Nursing & 57 & 29.1 & $48.6 \pm 8.6$ & \\
\hline Bachelor Degree in Nursing & 40 & 20.4 & $49.8 \pm 9.5$ & \\
\hline $\begin{array}{l}\text { Years of experience } \\
1-<6\end{array}$ & 75 & 38.2 & $49.3 \pm 8.9$ & \multirow{3}{*}{$\begin{array}{l}F=0.8 \\
P=0.5\end{array}$} \\
\hline $6-10$ & 35 & 17.9 & $47.6 \pm 8.4$ & \\
\hline$>10$ & 86 & 43.9 & $49.8 \pm 8.6$ & \\
\hline Current position & 164 & 83.2 & $49.3 \pm 8.6$ & \multirow{4}{*}{$\begin{array}{l}F=0.3 \\
P=0.8\end{array}$} \\
\hline Head nurse & 17 & 9.2 & $49.3 \pm 10.1$ & \\
\hline Supervisor & 9 & 4.6 & $47.8 \pm 6.5$ & \\
\hline Others & 6 & 3.1 & $46.2 \pm 11.5$ & \\
\hline
\end{tabular}

$*(\mathrm{P}=<0.05)$

Table (3): demonstrates the relation between nurses' perception regarding their work environment and their personal characteristics. As shown in the table there were no significant differences between personal characteristics and work environment except departments $(\mathrm{P}=\leq 0.05)$. Nurses of the medical department had the highest mean scores 52.3 \pm 6.9 regarding their work environment than other departments. Concerning age, nurses in the 20-30 age group; they had the highest mean scores $49.3 \pm 8.6$ regarding their work environment. The results demonstrated that married nurses had the highest mean scores $49.3+8.2$, nurses with a bachelor's degree had the highest mean scores $49.8 \pm 9.5$, nurses with more than ten years of expertise had the highest mean scores $49.8 \pm 8.6$ and staff nurses had the highest mean scores $49.3 \pm 8.6$ regarding their work environment. 
RELATION BETWEEN WORK ENVIRONMENT AND etc ...

\begin{tabular}{|c|c|c|c|c|c|c|c|c|}
\hline \multirow{3}{*}{ Levels of burnout } & \multicolumn{8}{|c|}{ Burnout subscales $(\mathrm{n}=196)$} \\
\hline & \multicolumn{2}{|c|}{$\begin{array}{c}\text { Personal } \\
\text { accomplishment }\end{array}$} & \multicolumn{2}{|c|}{ Depersonalization } & \multicolumn{2}{|c|}{$\begin{array}{l}\text { Emotional } \\
\text { exhaustion }\end{array}$} & \multicolumn{2}{|c|}{ Total burnout } \\
\hline & No & $\%$ & No & $\%$ & No & $\%$ & No & $\%$ \\
\hline Low & 75 & 38.3 & 52 & 26.5 & 64 & 32.7 & 61 & 31.1 \\
\hline Moderate & 59 & 30.1 & 79 & 40.3 & 63 & 32.1 & 68 & 34.7 \\
\hline High & 62 & 31.6 & 65 & 33.2 & 69 & 35.2 & 67 & 34.2 \\
\hline
\end{tabular}

Table (5): illustrates levels of burnout among nurses. Results revealed that $34.7 \%$ and $34.2 \%$ of nurses had a moderate and high level of exhaustion, respectively. As shown in the table, more than one-third of nurses $(35.2 \%)$ had a higher levels regarding emotional exhaustion and $(38.3 \%)$ had a low personal accomplishment, respectively. More than onethird of nurses $(40.3 \%)$ had a moderate level of depersonalization subscale.

Table (5): The Relation between Nurses' Perception of Burnout and Their Age

\begin{tabular}{|l|c|c|c|c|c|}
\hline \multirow{2}{*}{ Age in years } & & $\begin{array}{c}\text { Emotional } \\
\text { Exhaustion }\end{array}$ & Depersonalization & $\begin{array}{c}\text { Personal } \\
\text { accomplishment }\end{array}$ & Total Burnout \\
\cline { 2 - 6 } & $\begin{array}{c}\text { Total } \\
\mathbf{n}=\mathbf{1 9 6}\end{array}$ & Mean $\mathbf{\text { SD }}$ & Mean \pm SD & Mean \pm SD & Mean \pm SD \\
\hline $20-30$ years & 158 & $34.3 \pm 9.1$ & $8.9 \pm 3.3$ & $29.9 \pm 6.6$ & $73.3 \pm 13.02$ \\
\hline More than 30 & 38 & $37.9 \pm 7.1$ & $9.5 \pm 4.03$ & $30.2 \pm 6.8$ & $77.6 \pm 10.2$ \\
\hline $\begin{array}{l}\text { Significance } \\
\text { test }\end{array}$ & & $\begin{array}{c}\mathrm{t}=2.3 \\
\mathrm{P}=0.01^{*}\end{array}$ & $\begin{array}{c}\mathrm{F}=0.4 \\
\mathrm{P}=0.6\end{array}$ & $\begin{array}{c}\mathrm{t}=0.2 \\
\mathrm{P}=0.9\end{array}$ & $\begin{array}{c}\mathrm{t}=1.9 \\
\mathrm{P}=0.05^{*}\end{array}$ \\
\hline
\end{tabular}

$*(\mathrm{P}=\leq 0.05)$

Table(5): reveals the relation between nurses' perception of burnout and their age. The table showed a significant difference between age groups of nurses and burnout and emotional exhaustion $(\mathrm{P}=\leq 0.05)$. It can be noticed nurses who were in the age group over 30 years had the highest mean scores $(77.6 \pm 10.2)$ of burnout.

Table (6): The Relation between Nurses' Perception of Burnout and Their Experience

\begin{tabular}{|l|l|l|l|l|l|}
\hline \multirow{2}{*}{$\begin{array}{c}\text { Years } \\
\text { of experience }\end{array}$} & \multirow{2}{*}{$\begin{array}{c}\text { Total } \\
\mathbf{n}=\mathbf{1 9 6}\end{array}$} & $\begin{array}{c}\text { Emotion } \\
\text { Exhaustion }\end{array}$ & Depersonalization & \multicolumn{1}{c|}{$\begin{array}{c}\text { Personal } \\
\text { accomplishment }\end{array}$} & \multicolumn{1}{c|}{ Total Burnout } \\
\cline { 3 - 6 } & & \multicolumn{1}{c}{ Mean \pm SD } & \multicolumn{1}{c|}{ Mean \pm SD } & Mean \pm SD & \multicolumn{1}{c|}{ Mean \pm SD } \\
\hline $1-<6$ & 75 & $35.3 \pm 8.2$ & $8.7 \pm 3.6$ & $30.9 \pm 6.04$ & $75.04 \pm 10.3$ \\
\hline $6-10$ & 35 & $38.4 \pm 5.8 * *$ & $8.8 \pm 3.5$ & $31.1 \pm 4.5$ & $79.8 \pm 6.9 * * *$ \\
\hline$>10$ & 86 & $33.4 \pm 9.9 * *$ & $10.2 \pm 3.8$ & $28.7 \pm 7.6$ & $71.00 \pm 15.2 * * *$ \\
\hline $\begin{array}{l}\text { Significance } \\
\text { test }\end{array}$ & $\begin{array}{l}\mathrm{F}=4.2 \\
\mathrm{P}=0.02 *\end{array}$ & $\begin{array}{l}\mathrm{F}=2.5 \\
\mathrm{P}=0.09\end{array}$ & $\begin{array}{l}\mathrm{F}=2.9 \\
\mathrm{P}=0.055\end{array}$ & $\begin{array}{l}\mathrm{F}=6.8 \\
\mathrm{P}=0.001 *\end{array}$ \\
\hline
\end{tabular}

$*(\mathrm{P}=\leq 0.05)$

Table (6): illustrates relation between nurses' perception of burnout and their experience. This table shows that there were significant differences between years of experience and 
burnout $(\mathrm{P}=0.001)$. Results denoted that nurses with experience of 6 to 10 years had the highest mean scores $(79.8 \pm 6.9)$ of burnout.

Table (7): Correlation between Work Environment and Burnout

\begin{tabular}{|c|c|c|}
\hline \multicolumn{2}{|c|}{$\mathbf{n}=\mathbf{1 9 6}$} & Total burnout \\
\hline \multirow{2}{*}{ Total work environment } & $\mathrm{R}$ & $-.314^{* *}$ \\
\cline { 2 - 3 } & $\mathrm{P}$ & $<0.0001^{* *}$ \\
\hline
\end{tabular}

Table (7): clarifies correlation between work environment and burnout. The table showed negative correlations between the total scores of work environment and burnout $(\mathrm{r}=\mathrm{-}$ $\left..314^{* *}, \mathrm{p}<0.0001^{* *}\right)$.

Table (8): Correlation between Work Environment and Burnout Subscales

\begin{tabular}{|c|c|c|c|c|}
\hline \multicolumn{2}{|l|}{ Subscales } & $\begin{array}{c}\text { Emotion } \\
\text { Exhaustion }\end{array}$ & Depersonalization & $\begin{array}{c}\text { Personal } \\
\text { Accomplishment }\end{array}$ \\
\hline \multirow[t]{2}{*}{ Involvement } & $\mathrm{K}$ & -.241 & $-.22 U$ &.- UUY \\
\hline & $r$ & .001 & $.0 U 2$ & yUd \\
\hline \multirow[t]{2}{*}{ Peer cohesion } & $\mathrm{K}$ & -.384 & $-.108-$ & .148 \\
\hline & $\mathrm{P}$ & .000 & .132 & .038 \\
\hline \multirow[t]{2}{*}{ Supervisor support } & K &.- Uช I & $-.1<1$ & $.10 y$ \\
\hline & $P$ & .257 & .076 & .018 \\
\hline \multirow[t]{2}{*}{ Autonomy } & K & $-.3 / 2$ & $-.24 J$ & $. U / 1$ \\
\hline & $r$ &. UUU & .001 & $.5 \angle 2$ \\
\hline \multirow[t]{2}{*}{ Task orientation } & $\mathrm{K}$ & -.074 & -.03 & .079 \\
\hline & $\mathrm{P}$ & .305 & 6 & .272 \\
\hline \multirow[t]{2}{*}{ Work pressure } & $\mathrm{K}$ & .133 & -.04 & -.151 \\
\hline & $r$ & .003 & .0 & .035 \\
\hline \multirow[t]{2}{*}{ Clarity } & $\mathrm{K}$ & -.268 & -.121 & .155 \\
\hline & $\mathrm{P}$ & .000 & .092 & .031 \\
\hline \multirow[t]{2}{*}{ Ivanagerial control } & K & -.181 & $-.18 y$ & .usy \\
\hline & $P$ & .011 & .008 & .585 \\
\hline \multirow[t]{2}{*}{ Innovation } & K & -0.3 & -0.2 & U.U/ \\
\hline & & $\leq 0.001$ & 0.002 & 0.4 \\
\hline \multirow[t]{2}{*}{ Physical comtort } & $\mathrm{K}$ & -0.2 & -0.1 & U.1 \\
\hline & $\mathrm{P}$ & 0.03 & 0.2 & 0.08 \\
\hline \multicolumn{5}{|l|}{$*(\mathrm{P}=\leq 0.05)$} \\
\hline \multicolumn{3}{|c|}{$\begin{array}{l}\text { Table (19): reveals correlation } \\
\text { between work environment and burnout } \\
\text { subscales. According to the table, all work } \\
\text { environment subscales were negatively } \\
\text { correlated with emotional exhaustion and } \\
\text { depersonalization except work pressure } \\
\text { was positively with emotional exhaustion. } \\
\text { While, all work environment subscales } \\
\text { were positive correlated with personal }\end{array}$} & \multicolumn{2}{|c|}{$\begin{array}{l}\text { VII. Discussion } \\
\text { A magnetic and supportive work } \\
\text { environment could be defined as an setting } \\
\text { that pulls persons into the health } \\
\text { professions, encouraging them to stay } \\
\text { within the staff of health and enabling } \\
\text { them to perform effectively (Wiskow et }\end{array}$} \\
\hline
\end{tabular}


al., 2010) ${ }^{3}$. Burnout may result from various variables in the workplace including workload, exposure to emotional burdens of patients' care, and perceived sense of insufficiency and reduced accomplishment (Mortada \& El Seifii, 2012) ${ }^{19}$.

\section{I-Results related to nurses' Perception regarding their work environment}

The results of the present study indicated that nearly half of nurses rated their work environments as negative. This result may be due to lack of interpersonal aspects in the working environment, for example cohesion and social collaboration between staff and in addition to the relationship and support provided by management and colleagues. In addition, lack of degree to encourage nurses personal growth through decision-making and autonomy and lack of degree of highlighting on using variation, change, and new styles.

The results of the present study were congruent with El Deeb et al., (2016) ${ }^{20}$ study, who found that the majority of nurse had a negative perception regarding their work environment. Also, the results were similar with Jernigan et al., (2016) ${ }^{21}$ study, who found that nurses rated their work environment as negative.

On the other hands, the results of the present study were inconsistent with Hayes (2015) ${ }^{22}$ study, who found that hemodialysis nurses perceived their work environment positively.

\section{II- Results related to work environment dimensions}

Regarding the work relationship dimension examined, the result of the present study showed that nurses had a lower degree of involvement. This may be due to there's not much group spirit, nurses does not seem to take pride in the hospital and few nurses ever volunteer. The result of the present study showed that nurses had lack of co-worker cohesion, this result may be related to nurses do not arrange to help a new nurse feel comfortable, the atmosphere is somewhat impersonal, rarely do things together after work, often does not eat lunch together, nurses who differ greatly from the others in the hospital don't get along well, and they often make trouble by talking behind the back of each other. Moreover, the result of the present study showed that nurses had a low level of supervisor support. This result may be due to supervisors do not tend to talk down to nurses, supervisors often criticize nurses on minor things, nurses generally do not feel free to ask for a promotion, supervisors expects too much from nurses and nurses don not discuss their personal problems with supervisors.

This result was inconsistent with Kotzer et al., (2011) ${ }^{\mathbf{2 3}}$, who assess nurses' perception of their real and ideal work environment in a pediatric tertiary care setting, they found that staff perceived high levels of peer cohesion, involvement, supervisor support in their work environment.

Concerning the personal growth work environment variables examined, nurses reported experiencing a low level of autonomy. This result may be due to few nurses have some important responsibilities, don not have the freedom to do as they like, are not heartened to make their own decisions, do not work enough independently of supervisors and supervisors do not meet regularly with nurses to discuss their future work goals.

The result of this study showed that nurses had a high level of task orientation. This result may be due to nurses pay a lot of attention to accomplishment their work, there's no a lot of wasted time because of ineffectiveness, nurses rarely postpone things until tomorrow, getting a lot of work done is essential to nurses, there's an highlighting on work before play, nurses 
work very hard, nurses seem to be fairly effective and there's no tendency for nurses to come late to work.

The present study revealed that nurses had a high level of work pressure, this may be due to there is continuous pressure to get work done, continuously there looks to be an urgency about everything, nurses cannot have enough time to relax, everyone works too hard, there is pressure of time, it is very hard to keep up with their assignment, It cannot be easy to do the job, there are always deadlines to follow and they often have to work overtime to do their job.

In the same line, Kotzer et al., $(\mathbf{2 0 1 1})^{23}$, found that staff perceived high levels of task orientation in their work environment and Wolf et al., (2011) ${ }^{\mathbf{2 4}}$, found that nurses working in specialized and general hospital units reported high work pressure and low autonomy.

In respect of the system maintenance and system change, nurses reported low levels of clarity. The result of this study may be due to nurses reported that things are sometimes quite disorganized, activities are not well-designed, regulations and rules are rather ambiguous and vague, outlying benefits are not totally explained to the nurses, and policies and rules are continuously changing.

The result of the present study showed low levels of innovation. This result may be due to nurses reported that their work environment would not be one of the first to work out a new idea, there is no a novel, fresh atmosphere about the place and things always seem not to be unchanging.

The present study revealed that nurses had low levels of physical comfort. This result may be due to nurses perceived their room conditions sometimes gets too hot, this place has not a fashionable and modern form, the place could support new interior decorations, the colors and decorations do not make the place warm and joyful to work and workplace is somewhat drafty (disorganized) sometimes.

The result of the present study showed that nurses had a high levels of managerial control. This result may be due to nurses reported that there's a firm stress on following regulations and policies, they cannot wear informal clothing while on the work if they want, nurses are expected to follow the rules for doing their work, supervisors save a rather close watch on nurses, supervisors are always observing nurses and supervise them very carefully, nurses are expected to follow quite firmly to the customs and rules, and if nurse comes late, they cannot compensate it by staying late.

These findings were inconsistent with Haque and Sheikh (2013) ${ }^{25}$, who found that the staff members of health care group perceived higher clarity, innovation, and physical comfort.

\section{III- Results related to relation between} nurses' perceptions regarding their work environment and their personal characteristics

The results of the current study revealed that nurses working at the medical department had higher scores regarding their work environment than others. This result may be related to awareness of what can be expected in their daily routine and most of their patients hesitate to the department, higher autonomy, skill base, the level of teamwork and communication.

In the same line, these findings supported the study conducted by Zein EI Din and Abd El Aal (2013) ${ }^{26}$, study, they found that nurses working in medical units perceived a more favorable working environment.

Results of this study were incongruent with Choi and Boyle (2014) ${ }^{27}$, study, they found that nurses in specialty units tended to have positive perception toward their 
practice environment compared with those practicing in general wards.

\section{IV- Results related to burnout among nurses}

Concerning burnout among nurses, the result of the present study revealed that more than one-third of nurses had a moderate level of burnout. This result may be due to of feelings of being emotionally over extended and exhausted by their work and impersonal response toward recipients of their service, care treatment, or instruction, factors such as age of the nurse, years of service, lack of adequate staff workload, poor leadership, lack of social support, conflict with physicians, presence of stressors related to private life. In the same line, the study done by Karkar et al., (2015) ${ }^{\mathbf{2 8}}$ and Jaafarpour et al., (2015) ${ }^{29}$ study, they found that nurses reported a moderate level of burnout regarding their workplaces. On the other hand, the finding of the present study was inconsistent with Skefales et al., (2014) ${ }^{\mathbf{3 0}}$ study, they found that Greek nurses had a high level of burnout.

\section{V- Results related to burnout dimensions}

Regarding emotional exhaustion, results of the current study indicated that more than one-third of nurses experienced high emotional exhaustion. This result may be due to nurses feel emotionally drained, feel used up at the end of the day, feel fatigued when they get up in the morning and have to face another day on the job, working with people all day is really a strain for them, feel burned out from their work, feel frustrated by my job, feel work too hard on their job, working directly with people puts too much stress on them and feel like they are at the end of their rope.

Results of this study were congruent with Hamaideh (2011) ${ }^{31}$ study, who found that level of emotional exhaustion was high among Jordanian mental health nurses.

Regarding depersonalization, results of this study revealed that over one-third of nurses reported a moderate level of depersonalization. This result may be due to nurses worry that this job is hardening me emotionally, feel patients blame them for some of their problems, lack of supervisors and co-workers support and less emphasis on innovation. These results reinforced by Gandi et al., (2011) ${ }^{32}$ search, they found that Nigerian nurses had moderate level of burnout. Furthermore, the outcome is inconsistent with Delpas et al., (2011) $)^{33}$ study, they discovered that nurses had the lowest level of depersonalization.

Regarding personal accomplishment, the result of this study presented that more than one-third of nurses experienced a low level of personal accomplishment.

This result may be related to nurses can easily understand how their patients feel about things, deal very efficiently with the problems of their patients, can easily create a relaxed atmosphere with their patients, have accomplished many worthwhile things in this job, in their work they deal with emotional problems very calmly, have high emphasis on task orientation and strength of the feeling of responsibility toward their work.

The results of this study were consistent with El-Demerdash et al., $(\mathbf{2 0 1 3})^{34}$ study, they found that all nurses in general medical surgical staff in their research had a low level of accomplishment. The results of the present study were incongruent with Cheng et al., (2015) ${ }^{35}$ study, they found that most nurses high percent of exhibited high level of personal accomplishment. 


\section{VI- Relation between nurses perception regarding burnout and} personal characteristics

Regarding the relation between the level of burnout and age, the present study revealed that a high burnout level and emotional exhaustion found in nurses in the age group more than 30 years old, while a low burnout level and emotional exhaustion found in nurses in the age group from 20 to 30 years old. This results may be due to have more responsibilities and depending on them more than younger nurses attributed to the fact that they are usually less experienced, lack of professional development opportunities and lack of training for work.

Results of this study were congruent with Khodadadizadeh et al., (2012) ${ }^{\mathbf{3 6}}$ study, they found that the highest level of burnout was observed among nurses in age group from 24-30 years old.

The study findings revealed that high level of burnout and emotional exhaustion found among experienced nurses from 6 to 10 years of experience. While low level of burnout and emotional exhaustion found in nurses experienced more than 10 years of experience.

This result may be due to role ambiguity and inability to deal with work complexity. Higher experienced nurses may have achieved a good position and more responsibilities as they gained experience regarding complex situations. In addition, nurses with the most nursing experience have the most experience with self-integration and can maintain a calm state of mind. Thus, they can put more energy and emotion into their work and utilize their potential in their nursing careers.

Results of the present study were consistent with the study done by Tekindal et al., (2012) ${ }^{37}$ and Al-Turki et al., $(\mathbf{2 0 1 0})^{\mathbf{3 8}}$, they reported that nurses with more years regarding work experience are less likely to experience burnout.

\section{VII- Correlation between Work \\ Environment and Burnout}

This study revealed that there was a significant negative correlation between work environment and burnout. The result of the present study was consistent with Zaki et al., (2016) ${ }^{39}$ study, they found that there is a statistically significant negative correlation between nurses' burnout and work environment. Also, Azri (2013) ${ }^{\mathbf{4 0}}$, stated that interaction between personal burnout and environmental factors and burnout syndrome are the most obvious in health care professionals and good work environment eliminates burnout.

\section{Conclusion}

The results of the present study revealed a negative correlation between work environment and nurses' burnout. Nearly half $(49.5 \%)$ of nurses rated their work environment as negative. The results revealed that more than one-third $(34.7 \%$ and $40.3 \%$ ) of nurses had a moderate level of burnout and depersonalization, respectively. More than one-third (35.2\% and $38.3 \%$ ) of nurses had a high level of emotional exhaustion and a low level of personal accomplishment, respectively.

\section{Recommendations}

In the light of the findings, the following recommendations were suggested:

\section{Improving work environment through:}

1. Providing staff development program for nurse managers on how to integrate staff nurses into decision-making and effectively address new ideas to promote organizational climate and psychological empowerment of nurses.

2. Providing a supportive environment through adequate supervisory and organizational support, peer relationships. 
3. Providing a pleasing physical environment, created interactive and engaging atmosphere (teamwork, positive and negative feedback, energetic and positive climate, collaboration and sharing)to ensure that individuals are physically comfortable at work.

4. Creating a greater sense of autonomy create a greater sense of autonomy through explaining to staff why their assignment or goal has value allow them to decide how they will reach goal try creating the feeling of choice by inviting them to make decisions about more peripheral aspects of the task.

\section{Management of burnout:}

1. Managers should be alert for signs of stress amongst their staff.

2. Providing systematic training courses for the nurses to manage the talent of stress management and improve healthy coping strategies to counteract the negative influences of workload.

3. Making adjustments to job open lines of communication with manager.

4. Dealing with conflict at an early stage and flowing upon actions.

Further research is recommended to determine the between time management and burnout. The role of task orientation and innovation on burnout.

\section{References}

1. Mehboob, F., and Bhutto, N. (2012): Job satisfaction as a Predictor of Organizational Citizenship Behavior a Study of Faculty Members at Business Institutes. International Conference on Business, Economics, Interdisciplinary Journal of Contemporary Research in Business, 3 (9): 1447-1455.
2. Chandrasekar, K. (2011): Workplace Environment and its Impact on Organizational Performance in Public Sector Organization. International Journal of Enterprise Computing and Business Systems, 1 (1): 1-19.

3.Wiskow, C., Albreht, T., and Pietro, C. (2010): How to create an attractive and supportive working environment for health professionals. Copenhagen; Report No. 15: 1-37.

4. Moos, R. (2008): Work Environment Scale: annotated bibliography- first and second editions. California: Mind Gardens, Inc

5. Wallgren, L. (2011): Motivation requested - Work motivation and the work environment of IT consultants. Department of Psychology, University of Gothenburg. Available at http://hdl.handle.net/2077/24074.

6. Liu, K., You, L., Chen, S., Hao, Y., Zhu, X., Zhang, L., and Aiken, L. (2012): The relationship between hospital work environment and nurse outcomes in Guangdong, China: A nurse questionnaire survey. Journal of Clinical Nursing, 21 (9-10): 14761485.

7. Maslach, C., and Leiter, M. (2009): Nurse turnover: the mediating role of burnout. J. Nurs. Manag, 17(3): pp 331-339. 10.1111/j.1365-2834.2009.

8. Khamisa, N. (2015): Work related stress, burnout, job satisfaction and general health of nurses. International Journal of Environmental Research and Public Health, 12 (1): 652- 666.

9. Barlem, E., Tomaschewski-Barlem, J., Lunardi, V., Lunardi, G., Silveira, R., and Vidal, D. (2014): Burnout syndrome among undergraduate nursing students at a public university. Revista LatinoAmericana de Enfermagem. 22(6): 934-941.

10. Maslach, C., and Leiter M. (2008): Early predictors of job burnout and 
engagement. Journal of Applied Psychology, 93 (3): 498-512.

11. Morse, G., Salyers, M., Rollins, A., Monroe-DeVita, M., and Pfahler, C. (2012): Burnout in mental health services: A review of the problem and its remediation. Administrative Policy in Mental Health, 39 (5): 341-352.

12.Pisanti, R., Lombardo, C., Lucidi, F., Violani, C., and Lazzari, D. (2013): Psychometric properties of the Maslach Burnout Inventory for Human Services among Italian nurses: a test of alternative models. Journal of Advanced Nursing, 69 (3): 697-707.

13.Suñer-Soler, R., Grau-Martín, A., Flichtentrei, D., Prats M, Braga, F., Font-Mayolas, S., and Gras, M. (2014): The consequences of burnout syndrome among healthcare professionals in Spain and Spanish speaking Latin American countries. Burnout Research., 1(2): 82-89.

14.Alidosti, M., Delaram, M., Dehgani, L., and Moghadam, M. (2016): Relationship Between Self-Efficacy and Burnout Among Nurses in Behbahan City, Iran, 3(4): 1-5 DOI: 10.17795/whb-30445.

15.Moos, R. (1994): Work Environment Scale Manual, (3rd Ed. ). Palo Alto, CA: Consulting Psychologists Press

16.Maqsood, A. (2011): Work Environment, Burnout, Organizational Commitment, and Role Of Personal Variables As Moderators, published doctorate thesis, Quaid-i-Azam University, Islamabad,p 90-91, retrieved at15/12/2014from https://books.google.com.eg/books?isb $\mathrm{n}=113564262$.

17.Maslach, C., Jackson, S., and Leiter, M. (1996): Maslach Burnout Inventory, (3rd Ed.). California: Consulting psychological press, Inc.

18. Lin, Q., Jiang, C., and Lam, T. (2013): The relationship between occupational stress, burnout, and turnover intention among managerial staff from a Sino-Japanese joint venture in Guangzhou, China. J Occup Health, 55(6): 458-67.

19.Mortada, E., and El Seifii, O. (2012): Clinicians burnout and career satisfaction across the major specialties in Zigzag University Hospitals. Journal of Applies Sciences Research. 8(8): 3961-3969.

20.Eldeeb, G., Ghoneim, A., and Eldesouky, E. (2016): Perception of Patient Safety Among Nurses at Teaching Hospital, American Journal of Nursing Science, 5 (4): 122-128.

21.Jernigan, E., Beggs, J., and Kohut, G. (2016): An examination of nurses' work environment and organizational commitment, Vol. 20 Issue 1, pp112131.

22.Hayes, B., Douglas, C., and Bonner, A. (2015): Work environment, job satisfaction, stress and burnout among hemodialysis nurses. Journal of Nursing Management, 23(5): 588598.

23.Kotzer, A., Koepping, D., and LeDuc, K. (2011): Perceived nursing work environment of acute care pediatric nurses, 32(4): 327-32

24.Wolf, J., Hanson, H., and Moir, M. (2011): Organization development in healthcare: conversations on research and strategies. Concluding remarks. Adv Health Care Manag., 10: 389-392.

25.Haque, A., and Sheikh, H. (2013): Employees' perceptions of work environment in certain setting of hyderabad city, $7(3-4)$ : $53-59$.

26.Zein El-Din, Y., and Abd El-Aal, N. (2013): The relationship between perceived safety climate, nurses' work environment and barriers to medication administration errors reporting. Life Science Journal, 10 (1): 950-961.

27.Choi, J., and Boyle, D. (2014): Differences in nursing practice environment among US acute care unit 
RELATION BETWEEN WORK ENVIRONMENT AND etc...

types: A descriptive study. 34.El-Demerdash, S., Basal, A., and
International Journal of Nursing Studies, 51(1): 1441-1449.

28.Karkar, A., Dammang, M., and Bouhaha, B. (2015): Stress and burnout among hemodialysis nurses: A single-center, prospective survey study. Saudi J Kidney Dis Transpl, 26 (1): 128.

29.Jaafarpour, M., Khani, A., and Mahmodian, M. (2015): Evaluation of the quality of nursing work life and its association with job burnout in Isfahan University of Medical Sciences, 2 (1): 30-39.

30.Skefales, A., Plakas, S., Fouka, G. , Goni, M., Vassiliadou, M., and Bergiannaki, J. (2014): Burnout and Its Association with Working Conditions among Greek Hospital Nurses in a Time of Financial Crisis. Open Journal of Nursing, 4 (7): 548563.

31.Hamaideh, S. (2011): Burnout, Social Support, and Job Satisfaction among Jordanian Mental Health Nurses, 32(4):pp.234-42

32.Gandi, J., Paul, S., Haruna, K., and Zubaira, K. (2011): The role of stress and level of burnout in job performance among nurses. Mental Health in Family Medicine, 8 (3): 181194.

33.Delpas, M., Raeissi, P., Begdeli, F., and Shahabi, M. (2011): The impact of job otation on nurses' burnout in Ayatollah Kashani Hospital,Tehran: A case study. Iran Occupational Health, 7 (4): 76-8.

Aldeeb, G. (2013): The Relationship between Burnout and Organizational Commitment among Nurses at Tanta University Hospitals, Volume 2, Issue $6: 20-28$.

35.Cheng, F., Meng, A., and Jin, T. (2015): Correlation between burnout and professional value in Chinese oncology nurses: A questionnaire survey, Volume 2, Issue 2: 153-157.

36.Khodadadizadeh, A., Ravari, A. Sayadi, A., Khodadadi, H., and Jafarinaveh, H. (2012): Occupational burnout assessment among nurses working in Iranian hospital of Ali-ebn Abitaleb, Rafsanjan-Iran, 1 (2): 103110.

37.Tekindal, B., Tekindal, M., Pinar G., Ozturk F., and Alan S. (2012): Nurses' burnout and unmet nursing care needs of patients' relatives in a Turkish State Hospital. International Journal of Nursing Practice, 18 (1): 68-76.

38.Al-Turki, H., Al-Turki, R., AlDardas, H., Al-Gazal, M., AlMaghrabi, G., Al-Enizi, N., and Ghareeb, B. (2010): Burnout syndrome among multinational nurses working in Saudi Arabia. Annals of African Medicine, 9 (4): .226-229.

39. Zaki, S., Elsayed, L., and Ibrahim, M. (2016): Factors Contributing to Burnout among Saudi Nurses and their Effect on Patients' Satisfaction at Makkah Al- Mukaramah Hospitals, 13 (5): 73-88.

40-Azri, B. (2013): Job satisfaction: A Literature review. Management Research and Practice, 3 (4): 77-86. 